\title{
Predictions of Solar Cycle 24
}

\author{
William Dean Pesnell
}

Received: 31 March 2008 / Accepted: 15 July 2008 / Published online: 21 August 2008

(C) The Author(s) 2008. This article is published with open access at Springerlink.com

\begin{abstract}
A summary and analysis of more than 50 predictions of the amplitude of the upcoming Solar Cycle 24 is presented. All of the predictions were published before solar minimum and represent our efforts to anticipate solar maximum at ever-earlier epochs. The consistency of the predictions within their assigned categories is discussed. Estimates of the significance of the predictions, compared to the climatological average, are presented.
\end{abstract}

\section{Introduction}

Solar-cycle predictions test our knowledge of the solar dynamo, a term that includes the processes involved in the production, transport, and destruction of solar magnetic field. Models of the dynamo are validated by their ability to predict solar activity over short and long timescales. Predictions of the magnitude and timing of Solar Cycle 24 are also used by a variety of space-weather groups to estimate orbital drag and other consequences of space weather in the upcoming cycle. Solar-activity predictions are used by space-weather operators to plan when to reboost satellites in low-Earth orbit, anticipate radiation exposure for current and upcoming missions, and to plan for outages in radio-based communication and navigation systems. Space-weather operators want to know the significance of each prediction when compared to other predictions.

Sunspot number $\left(R_{z}\right)$ is the most commonly predicted solar activity index. The rate of solar flares and amount of energy they release are well correlated with the sunspot number, as is the rate of coronal mass ejections. Cosmic rays, whose flux is anticorrelated with the solar cycle, are a significant source of radiation hazard in space. Geomagnetic activity has one component that is proportional to $R_{z}$ and another, which can be a source of significant space weather, that resembles the sunspot number but shifted forward several years (about a quarter cycle). But, in general, the sunspot number (or a proxy index such as F10.7, the spectral irradiance at a radio wavelength of $10.7 \mathrm{~cm}$ ) is the basic quantity needed for spaceweather work. The amplitude of the annual-averaged sunspot number for Solar Cycle $n$ will be called $R_{n}$.

W.D. Pesnell (凶)

Code 671, NASA Goddard Space Flight Center, Greenbelt, MD, USA

e-mail: william.d.pesnell@ nasa.gov 
We report here a summary and discussion of the predictions of Solar Cycle 24. The predictions are analyzed within categories to determine trends and consistencies. We also calculate whether each prediction would be considered significantly different from one of the simplest predictions: That Solar Cycle 24 will be a cycle of average amplitude and duration.

\section{Predictions of Cycle 24}

The Solar Cycle 24 Prediction Panel was convened in October 2006 to develop a consensus prediction of Solar Cycle 24. To ensure that a wide range of predictions were considered, predictions of the amplitude and timing of Solar Cycle 24 were solicited from the community in the categories of Fun, Precursor, Spectral, Climatology, Recent climatology, Neural network, Physics-based, or Other. The call for predictions was published in several newsletters, including the 15 August 2006 "Solar News" (http://solarnews.nso.edu).

The more than 50 predictions in Table 1 are a combination of 15 predictions submitted in response to the call by the Solar Cycle 24 Prediction Panel, four predictions described here, six predictions produced by the Prediction Panel, with the remaining predictions culled from the refereed literature. The table is organized by the predicted sunspot maximum and includes the predicted maximum sunspot number (value and timing), category of prediction, a short summary of method, and the reference. The third column of Table 1 contains a oneletter abbreviation of the category for each prediction. If a prediction was found during the literature search, the category was assigned by the author. No predictions were received or discovered in the categories Fun or Other. Another summary list of predictions was given by Janssens $(2005,2006)$. The category "Physics-based models" was renamed "Dynamo model" to more accurately reflect the nature of the expected predictions. Four predictions (Thompson (1993), aa_min, aa_4yr, and modified Feynman) were developed during the deliberations of the panel and two consensus predictions were released by the panel (Biesecker, 2007). The consensus predictions were not placed into categories. The references, predicted maxima, and uncertainties are shown in the bottom part of Figure 1. Categories for each prediction are shown by a color coding listed in the upper panel.

Some predictions of Solar Cycle 24 are not included in Table 1. A prediction by Li, Gao, and Su (2005) was omitted as they included multiple predictions, depending on the timing of solar minimum and rise time of Cycle 24. Some of their conditions have already passed; their remaining predictions are that the current solar minimum will be reached in June 2008 ( \pm two months), the next maximum will be in February 2013 ( \pm eight months), and the maximum will be about 137 or 80 , depending on whether the cycle is a fast riser or a slow riser. Volobuev and Makarenko (2008) used a combination of the sunspot number and radiocarbon variations to estimate that the upcoming decade will be smaller than the last but did not convert this into a prediction of $R_{24}$.

It is necessary to have quantitative estimates of the uncertainty of the predictions - in both magnitude and timing. Most of the amplitude predictions included either an error estimate or a range that could be converted into an error estimate. Timing predictions were less precise and usually depend on the timing of solar minimum. As we move into Cycle 24, those timing predictions that depend on the time of minimum and the shape of the rise will become more accurate. Although the timing predictions are listed in Table 1, they will not be discussed further. 
Table 1 Predictions of Solar Cycle 24.

\begin{tabular}{|c|c|c|c|c|}
\hline \multicolumn{2}{|c|}{ Predicted maximum } & \multirow{2}{*}{\multicolumn{2}{|c|}{ Category ${ }^{1}$ and summary }} & \multirow[t]{2}{*}{ Author and date } \\
\hline$R_{24}$ & Timing & & & \\
\hline 185 & $2010-2011$ & $\mathrm{C}$ & $\begin{array}{l}\text { Projection of last five cycles } \\
\text { (JSC) }\end{array}$ & Horstman (2005) \\
\hline $180 \pm 32$ & - & $\mathrm{P}$ & Disturbed days (panel) & Thompson $(1993)^{2}$ \\
\hline 180 & 2014 & $\mathrm{~S}$ & $\begin{array}{l}\text { Modified global minimum } \\
\text { analysis }\end{array}$ & $\begin{array}{l}\text { Tsirulnik, Kuznetsova, and } \\
\text { Oraevsky (1997) }\end{array}$ \\
\hline $152-197$ & - & $\mathrm{P}$ & $\begin{array}{l}\text { Integral of sunspot number used } \\
\text { as precursor }\end{array}$ & $\begin{array}{l}\text { Podladchikova, Lefebvre, and } \\
\text { Van der Linden (2006) }\end{array}$ \\
\hline $155-180$ & - & $\mathrm{D}$ & $\begin{array}{l}\text { Modified flux-transport dynamo } \\
\text { model calibrated with historical } \\
\text { run of sunspot area }\end{array}$ & $\begin{array}{l}\text { Dikpati, de Toma, and Gilman } \\
\text { (2006) }\end{array}$ \\
\hline $160 \pm 25$ & - & $\mathrm{P}$ & Analysis of aa index & Hathaway and Wilson (2006) \\
\hline $160 \pm 54$ & 2010.6 & $\mathrm{R}$ & $R_{24}=R_{22}($ even - odd $)$ & Current work \\
\hline 148 & & $\mathrm{P}$ & aa at minimum (panel) & aa_min (2006) \\
\hline 145 & 2009.96 & $\mathrm{~N}$ & Neural network forecast & Maris and Oncica (2006) \\
\hline $145 \pm 30$ & 2010 & $\mathrm{D}$ & $\begin{array}{l}\text { Fast meridional circulation } \\
\text { speed during cycle } 22 \text { leads to a } \\
\text { strong solar cycle } 24\end{array}$ & Hathaway and Wilson (2004) \\
\hline 145 & $2011-2012$ & $\mathrm{~N}$ & $\begin{array}{l}\text { Spectral analysis and neurofuzzy } \\
\text { modeling }\end{array}$ & Gholipour et al. (2005) \\
\hline 144 & - & $\mathrm{P}$ & aa during decline of 23 & Jain (2006) \\
\hline $142 \pm 24$ & - & $\mathrm{P}$ & aa at solar minimum & Kane (2007) \\
\hline $140 \pm 20$ & 2011.80 & - & $\begin{array}{l}\text { Panel consensus prediction } \\
\text { (high) }\end{array}$ & \\
\hline 140 & 2012.5 & $\mathrm{P}$ & Disturbed days analysis & Chopra and Dabas (2006) \\
\hline $135 \pm 20$ & & $\mathrm{P}$ & $\mathrm{aa} / R_{z}$ precursor (panel) & Modified Feynman $(2006)^{3}$ \\
\hline $134 \pm 50$ & 2011.7 & $\mathrm{C}$ & $\begin{array}{l}\text { Based on average of the last } \\
\text { eight solar cycles }\end{array}$ & Kennewell and Patterson (2006) \\
\hline 133 & 2009.5 & $\mathrm{C}$ & Statistics of $\sqrt{R_{z}}$ & $\begin{array}{l}\text { Tritakis, Mavromichalaki, and } \\
\text { Giouvanellis (2006) }\end{array}$ \\
\hline $130 \pm 15$ & - & $\mathrm{P}$ & $\begin{array}{l}\text { Complexity of } \mathrm{H} \alpha \text { synoptic } \\
\text { charts }\end{array}$ & Tlatov (2006) \\
\hline $124 \pm 30$ & - & $\mathrm{P}$ & Value of aa at solar minimum & Nevanlinna (2007) \\
\hline $124 \pm 23$ & - & $\mathrm{P}$ & Number of disturbed days in Ap & Dabas et al. (2008) \\
\hline 124 & & $\mathrm{C}$ & Statistics of equal phase average & $\begin{array}{l}\text { Khramova, Krasotkin, and } \\
\text { Kononovich (2002) }\end{array}$ \\
\hline $122 \pm 6$ & 2010.88 & $\mathrm{C}$ & $\begin{array}{l}\text { Statistical analysis of cycle para- } \\
\text { meters }\end{array}$ & $\begin{array}{l}\text { Kim, Wilson, and Cucinotta } \\
\text { (2006) }\end{array}$ \\
\hline $120 \pm 60$ & 2011.167 & $\mathrm{C}$ & $\begin{array}{l}\text { Modified McNish-Lincoln } \\
\text { model (MSAFE) }\end{array}$ & Euler and Smith (2006) \\
\hline $120 \pm 45$ & 2010.0 & $\mathrm{R}$ & $R_{24}=R_{23}$ (inertial) & Current work \\
\hline $120 \pm 25$ & & $\mathrm{P}$ & Behavior of aa (panel) & aa_4yr (2006) \\
\hline $116 \pm 13.2$ & $2012-1013$ & S & Spectral analysis of $R_{z}$ & Echer et al. (2004) \\
\hline $115 \pm 40$ & 2011.3 & $\mathrm{C}$ & $R_{24}=R_{z, \text { ave }}$ (average) & Current work \\
\hline
\end{tabular}


Table 1 (Continued)

\begin{tabular}{|c|c|c|c|c|}
\hline \multicolumn{2}{|c|}{ Predicted maximum } & \multicolumn{2}{|c|}{ Category ${ }^{1}$ and summary } & \multirow[t]{2}{*}{ Author and date } \\
\hline$R_{24}$ & Timing & & & \\
\hline $115 \pm 30$ & - & $\mathrm{P}$ & Number of disturbed days & Rabin (2007) \\
\hline $115 \pm 28$ & 2010.5 & $\mathrm{P}$ & Precursor + nonlinear dynamics & Sello $(2006)^{4}$ \\
\hline $115 \pm 15$ & - & $\mathrm{P}$ & $\begin{array}{l}\text { Area of high-latitude unipolar } \\
\text { regions }\end{array}$ & Tlatov (2006) \\
\hline $115 \pm 13$ & - & $\mathrm{P}$ & $\begin{array}{l}\text { Large-scale magnetic field, pre- } \\
\text { sented at October panel meeting }\end{array}$ & Tlatov (2006) \\
\hline $114.8 \pm 17.4$ & - & $\mathrm{C}$ & Cycle $n+1 \propto$ decline of $n-2$ & Du and Du (2006) \\
\hline $114 \pm 43$ & - & $\mathrm{C}$ & Mean of cycles $1-23$ & Prochasta (2006) \\
\hline 112 & - & $\mathrm{S}$ & $\begin{array}{l}\text { Combined empirical mode de- } \\
\text { composition and autoregression }\end{array}$ & Xu et al. (2008) \\
\hline $111 \pm 18$ & - & $\mathrm{P}$ & Minimum value of Ap & Thompson (2008) \\
\hline $110 \pm 65$ & 2/2011 & $\mathrm{C}$ & $\begin{array}{l}\text { Modified McNish-Lincoln } \\
\text { model (MSAFE) }\end{array}$ & Euler and Smith (2006) \\
\hline $110 \pm 15$ & - & $\mathrm{S}$ & Transfer function model & de Meyer (2003) \\
\hline $110 \pm 11$ & 2012 & $\mathrm{~S}$ & Autoregressive model & Hiremath (2008) \\
\hline $110 \pm 10$ & - & $\mathrm{P}$ & $\begin{array}{l}\text { Dipole-octupole magnetic mo- } \\
\text { ments }\end{array}$ & Tlatov (2006) \\
\hline $108 \pm 38$ & 2011 & $\mathrm{C}$ & $\begin{array}{l}\text { Skewness of previous cycles } \\
\text { separated into even/odd cycles }\end{array}$ & Lantos (2006) \\
\hline $105 \pm 9$ & $2010-2011$ & $\mathrm{~S}$ & $\begin{array}{l}\text { Extrapolation of dominant spec- } \\
\text { tral components found by MEM }\end{array}$ & Kane (1999) \\
\hline $101 \pm 20$ & 2012.5 & $\mathrm{~S}$ & Autoregressive, linear prediction & Current work \\
\hline $83.2-119.4$ & 2012.21 & $\mathrm{C}$ & $\begin{array}{l}\text { Statistical characteristics of solar } \\
\text { cycles }\end{array}$ & Wang et al. $(2002)^{5}$ \\
\hline $91.9 \pm 27.9$ & 2011.04 & $\mathrm{~S}$ & Autoregressive, moving average & Roth (2006) \\
\hline $90.7 \pm 9.2$ & - & $\mathrm{P}$ & $\begin{array}{l}\text { Number of spotless days at min- } \\
\text { imum }\end{array}$ & Hamid and Galal (2006) \\
\hline $90 \pm 10$ & $8 / 2012$ & - & $\begin{array}{l}\text { Panel consensus prediction } \\
\text { (low) }\end{array}$ & \\
\hline
\end{tabular}

\section{Categorized Predictions}

A summary of the predictions in each category is listed in Table 2. The columns show the category of the prediction, the number of predictions of each category in Table 1, the average and standard deviation of the predictions within the category, and the range of the predictions. The definition of the categories and the general characteristics of the predictions in each category are discussed in the following. The first entry in Table 2 is the average of all predictions in Table 1. The precursor category is expanded into subcategories to show the consistency within the subcategories.

\subsection{Climatology}

A climatological forecast assumes that the future behavior of a system is a function of the averaged behavior from the past. Predictions using statistical analyses of sunspot numbers were placed into this category. An example is that $R_{24}$ will be the climatological average, or 
Table 1 (Continued)

\begin{tabular}{|c|c|c|c|c|}
\hline \multicolumn{2}{|c|}{ Predicted maximum } & \multicolumn{2}{|c|}{ Category $^{1}$ and summary } & \multirow[t]{2}{*}{ Author and date } \\
\hline$R_{24}$ & Timing & & & \\
\hline $87.5 \pm 23.5$ & - & $\mathrm{S}$ & $\begin{array}{l}\text { Coupling between sunspot max- } \\
\text { ima and aa minima modulations } \\
\text { (wavelet analysis) }\end{array}$ & Duhau (2003) \\
\hline $80 \pm 21$ & 2012 & $\mathrm{~S}$ & $\begin{array}{l}\text { Mathematical theory of nonlin- } \\
\text { ear dynamics; predicts a long cy- } \\
\text { cle lasting } 12 \text { years }\end{array}$ & Baranovski (2006) \\
\hline $80 \pm 30$ & 2012 & $\mathrm{P}$ & Solar polar field precursor & Schatten (2005) \\
\hline 80 & - & $\mathrm{D}$ & Flux-transport dynamo model & $\begin{array}{l}\text { Choudhuri, Chatterjee, and } \\
\text { Jiang (2007) }\end{array}$ \\
\hline $74 \pm 10$ & - & $\mathrm{P}$ & $\begin{array}{l}\text { Statistics of low-latitude sunspot } \\
\text { groups }\end{array}$ & Javaraiah (2007) \\
\hline $70 \pm 2$ & - & $\mathrm{P}$ & $\begin{array}{l}\text { Polar magnetic field strength at } \\
\text { solar minima }\end{array}$ & $\begin{array}{l}\text { Svalgaard, Cliver, and Kamide } \\
(2005)^{6}\end{array}$ \\
\hline $70 \pm 17.5$ & 2012.96 & $\mathrm{~S}$ & $\begin{array}{l}\text { Statistical Gaussian-based ex- } \\
\text { trapolation }\end{array}$ & Kontor (2006) \\
\hline$<50$ & $2010-2011$ & $\mathrm{C}$ & $\begin{array}{l}\text { Statistics of the } 5303 \AA \text { coronal } \\
\text { line }\end{array}$ & $\begin{array}{l}\text { Badalyan, Obridko, and Sykora } \\
\text { (2001) }\end{array}$ \\
\hline $42 \pm 35$ & - & $\mathrm{S}$ & $\begin{array}{l}\text { Periods in } R_{z} \text { and radiocarbon } \\
\text { isotopic abundances }\end{array}$ & Clilverd et al. (2006) \\
\hline low & - & $\mathrm{C}$ & $\begin{array}{l}\text { Observations of flare energy } \\
\text { release during the descending } \\
\text { phase of cycle } 23 \text { (empirical) }\end{array}$ & $\begin{array}{l}\text { Mariş, Popescu, and Beşliu } \\
(2004)^{7}\end{array}$ \\
\hline
\end{tabular}

\footnotetext{
${ }^{1}$ The third column is a one-letter description of the method: C, Climatology; D, Dynamo model; N, Neural network; P, Precursor; R Recent climatology; or S, Spectral.

${ }^{2}$ Thompson (1993) used the method described in Thompson (1993) with data updated through 2006.

${ }^{3}$ This prediction was created during the panel deliberations using the method of Hathaway and Wilson (2006).

${ }^{4}$ This prediction is based on the method of Sello (2003).

${ }^{5}$ The average of the predictions given by Wang et al. (2002) is listed in Table 1.

${ }^{6}$ The prediction of Svalgaard, Cliver, and Kamide (2005) was updated at the panel meeting from $75 \pm 8$ to $70 \pm 2$.

${ }^{7}$ The predicted maximum of Mariş, Popescu, and Beşliu (2004) was set to 40 in Figure 1.
}

the average of all previous maxima. Using the information from NOAA (2006), we calculate this to be $R_{z \text {,ave }}=115 \pm 40$ using all of the numbered solar cycles in the referenced table. This also provides an error estimate for judging the predictions. Timing information can be derived in a similar way. The average time between solar maxima is $11 \pm 1.5$ years, so Cycle 24 will peak in April 2011, 11 years from the maximum of Cycle 23.

The utility of climatological forecasts can be seen by the large number submitted to the panel and found in the literature. The largest and smallest predictions of $R_{24}$ are in this class. The average of predictions in this category is very close to the actual climatological average.

\subsection{Recent Climatology}

Recent climatology refers to a forecast where future behavior is related to behavior in the recent past. Two examples are the "inertial" forecast, $R_{24}=R_{23}$, in which it is assumed the 

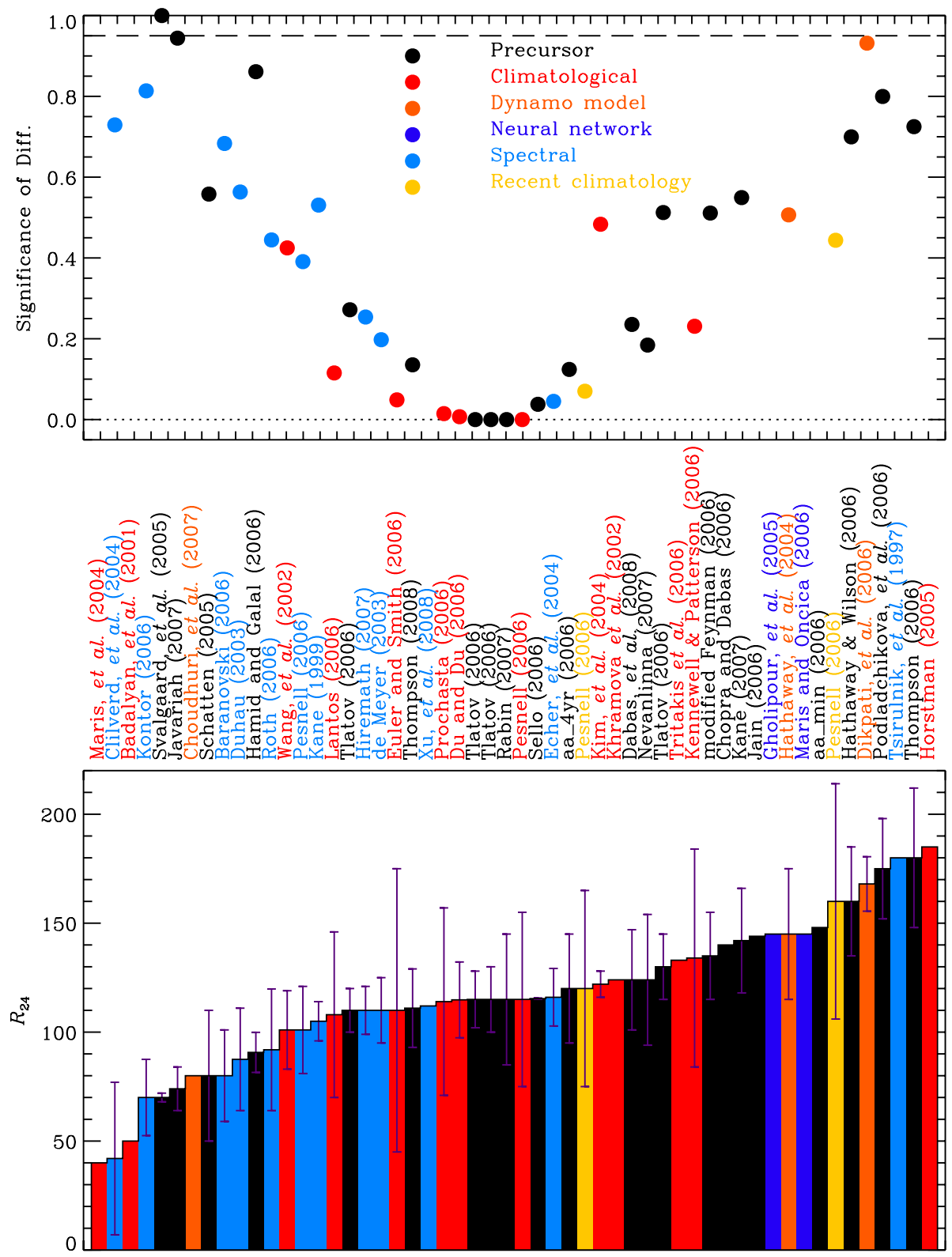

Figure 1 The predictions from Table 1, plotted in order of increasing predicted maximum for Cycle 24. The prediction categories are color coded as in the top panel. The upper plot is the significance of the difference from the climatological average of $115 \pm 40$ for those predictions that included an error bar. The dashed line shows the estimated "highly significant" level, which one prediction reaches. Two other predictions are statistically significant at the $90 \%$ level.

initial conditions of the system will persist throughout the entire period of the forecast, and the "even - odd cycle" forecast, $R_{24}=R_{22}$, which relies on the observation that solar cycles 
Table 2 Summary of predictions for Solar Cycle 24.

\begin{tabular}{lrrr}
\hline Category & Number & Average & \multicolumn{1}{c}{ Range } \\
\hline All & 54 & $117 \pm 33$ & $40-185$ \\
Climatology (C) & 13 & $111 \pm 36$ & $40-185$ \\
Recent climatology (R) & 2 & $140 \pm 30$ & $120-160$ \\
Dynamo models (D) & 3 & $131 \pm 45$ & $80-168$ \\
Spectral (S) & 12 & $100 \pm 33$ & $42-180$ \\
Neural network (N) & 2 & 145 & $145-145$ \\
Precursor (P) & 22 & $124 \pm 30$ & $70-180$ \\
$\quad$ Geomagnetic (mostly aa) & 12 & $137 \pm 20$ & $111-180$ \\
$\quad$ aa & 7 & $140 \pm 14$ & $120-160$ \\
$\quad$ Ap & 5 & $134 \pm 28$ & $111-180$ \\
Solar & 10 & $110 \pm 30$ & $70-175$ \\
$\quad$ Polar fields & 3 & $88 \pm 24$ & $70-115$ \\
$\quad$ Other solar & 7 & $116 \pm 32$ & $74-175$ \\
\hline
\end{tabular}

are organized into even and odd cycles with alternating amplitude. The inertial forecast is used in weather forecasting as a base forecast.

Both of these forecasts were derived by using the information in NOAA (2006) and were for above average activity in Cycle 24 and have larger errors than the climatological average. Standard deviations for this prediction category were calculated from the variance of the forecast and actual values (summed over the numbered solar cycles).

\subsection{Precursor}

Precursor forecasts, which look for leading indicators of solar activity, were the most common category of predictions. Two types of precursors dominate this category:

1. Solar polar magnetic field at minimum $\approx$ level of activity at next maximum: The three predictions in this category tend to be near or below average for Cycle 24.

2 . Geomagnetic activity near minimum $\approx$ level of activity at next maximum. Seven of the 12 geomagnetic precursor predictions in Table 1 used aa as their indicator of geomagnetic activity, four used Ap, and one used both. All of the predictions were for average to above average levels of activity in Solar Cycle 24.

The remaining precursor predictions used solar properties such as global magnetic field and have a wide divergence in their forecasts.

\subsection{Dynamo Model}

Dynamo model forecasts are produced by models capable of integrating conservation equations. They can include data-assimilation models. This is the first time that predictions in this category are available. The two most complete models (Dikpati, de Toma, and Gilman, 2006; Choudhuri, Chatterjee, and Jiang, 2007) predict high and low solar activity, respectively. Cameron and Schüssler (2007) discuss the progress and problems in using these models for predictions of solar activity. 


\subsection{Spectral}

A spectral forecast examines a Fourier analysis of the sunspot time series for invariant quantities such as frequencies whose amplitudes are conserved or have a simple time dependence. Wavelet-based and autoregressive forecasts were classified as spectral. The sunspot number was one of the first time series analyzed with autoregressive techniques (Yule, 1927). Three autoregressive forecasts of $R_{24}$ (two submitted and one created during the construction of Table 1) agree in predicting below-average activity for Solar Cycle 24.

Forecasts in the spectral category tended to predict that Solar Cycle 24 will have slightly below average activity. Only one was for a very high amplitude, whereas another provided the lowest quantitative prediction, the possibility that we will see the lowest solar activity since the Dalton minimum in the early 1800s (Clilverd et al., 2006).

\subsection{Neural Network}

A neural network forecast is derived from a set of nonlinear, statistical, data-modeling algorithms. They are used to determine and model complex relationships between inputs and outputs or to find patterns in data that can be extrapolated. Neural networks can be combined with other techniques, including spectral methods, to increase their accuracy. The two neural network forecasts for Solar Cycle 24 agree in their prediction of an above-average Cycle 24.

Figure 2 shows the categorized predictions with the one- $\sigma$ error drawn as a colored box and the range within the category drawn as an error bar. The precursor category is also shown split into components to allow comparison of the various methods. The dashed line is drawn at $R_{24}=115$, showing that almost all of the categories include $R_{z \text {,ave }}$ in their predictions, with the aa precursor class the exception. The disagreement of the solar polar and geomagnetic precursors is large enough to recommend they not be considered equivalent classes.

\section{Significance of Predictions}

Operational users of solar-activity predictions require predictions with an error estimate that allows the statistical significance of each prediction to be determined. One estimate of the statistical significance is to calculate the significance of the difference of the new forecast from a known forecast. If the significance is high $(>0.95)$, then the new forecast differs from the old and the effects of the new forecast should be considered. If the significance is low $(<0.90)$, then the new forecast has a high likelihood that it is drawn from the same probability distribution function as the existing forecast.

One a priori prediction is the climatological average of previous maxima $\left(R_{z, \text { ave }}\right)$. It is based on all previous maxima, has an error estimate, and does not vary wildly from cycle to cycle. Based on the discussion in Press et al. (1992), Mandel (1964), and Keeping (1962), we will use Student's $t$-test to determine whether each prediction differs significantly from $R_{z \text {,ave }}$. Only those predictions that provide an error estimate are included in this analysis.

From Section 3.1 we have $R_{z \text {,ave }}=115$ from 23 previous maxima and will define $\sigma_{0}$ as 40 and $\sigma_{P}$ as the error of the prediction. The variance of the difference is

$$
\sigma_{T}^{2}=\sigma_{0}^{2} / 23+\sigma_{P}^{2}
$$




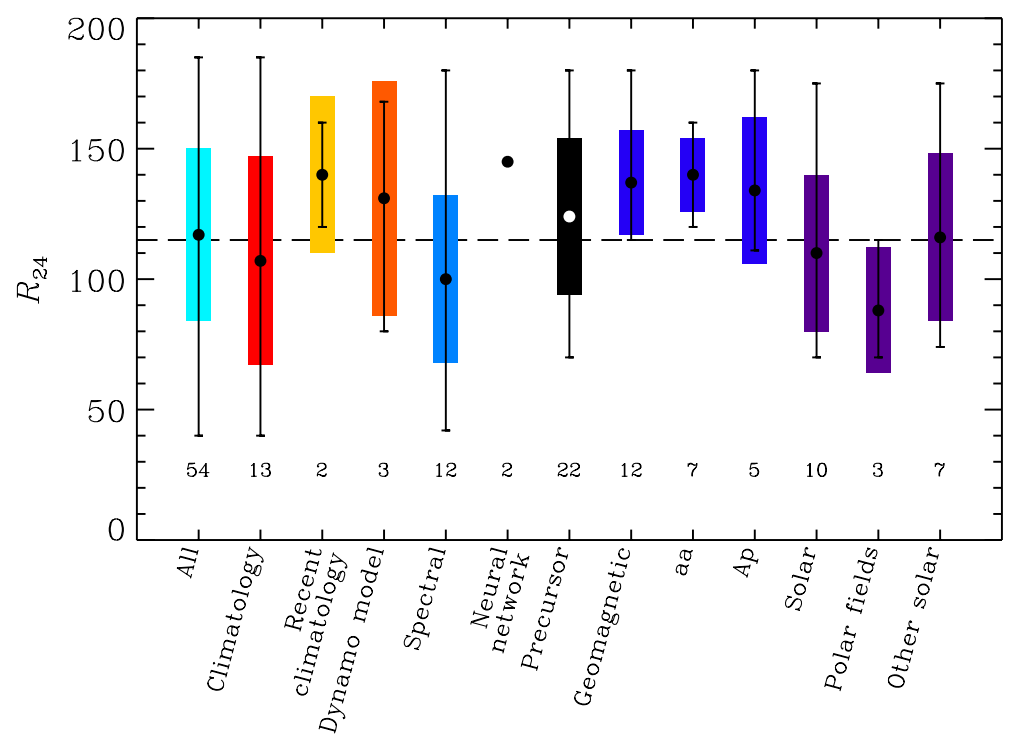

Figure 2 The categorized predictions in Table 2. The dot is the average prediction in each category, the color bar is drawn at the one- $\sigma$ error limits, and the error bars show the range of each category. Except for the breakouts of the precursor class, the colors correspond to those in Figure 1. The number of predictions in each category is written under the symbols. A dashed horizontal line is drawn at $R_{24}=115$.

the $t$ variable is

$$
t_{\text {test }}=\left(R_{24, P}-R_{z, \text { ave }}\right) / \sigma_{T},
$$

and the number of degrees of freedom are given by (Press et al., 1992)

$$
n_{f}=\left(\sigma_{0}^{2} / 23+\sigma_{P}^{2}\right)^{2} /\left[\left(\sigma_{0}^{2} / 23\right)^{2} / 22+\sigma_{P}^{4}\right] .
$$

The significance of the difference is given by Student's probability distribution function (Press et al., 1992; Keeping, 1962; Mandel, 1964):

$$
\operatorname{Pr}=A\left(t_{\mathrm{test}} \mid n_{f}\right) .
$$

The probability function is related to the incomplete beta function and is plotted in the upper panel of Figure 1. A level of significance must be selected. For this problem, $\operatorname{Pr}>0.95$ is a valid choice for a highly significant difference, meaning that there is a 1 in 20 chance that the predictions are the same.

The upper panel of Figure 1 shows that over half (24) of the 41 predictions with error estimates differ from $R_{z}$,ave with a level of significance below 0.5 . Two effects contribute to the statistical significance of the difference. Predicted values that differ from $R_{z}$,ave by the sum of their error estimates have $t_{\text {test }}>1$, increasing their statistical significance. This gives the general behavior of values near one at the high and low limits and small significance in the middle. A smaller effect is how $n_{f}$ behaves when $\sigma_{P}^{2} \ll \sigma_{0}^{2} / 23$, which increases $n_{f}$ and can add about 0.1 to the calculated significance. This is the case for Svalgaard, Cliver, and Kamide (2005), who give $\sigma_{P}=2$ and thus gain some significance. The predictions of Javaraiah (2007) and Dikpati, de Toma, and Gilman (2006) benefit to a lesser extent from this effect, both being significant at the $90 \%$ level. 


\section{Summary and Conclusions}

The convergence of the climatology predictions to $R_{z, \text { ave }}$ is not surprising, but the large discrepancy in the dynamo models shows that those models do not as yet possess a predictive capability. The precursor category must be further broken out into solar and geomagnetic to produce equivalent classes, illustrating the poor overlap of the two techniques. Precursors were a major contributor to the consensus prediction of Solar Cycle 23 (Joselyn et al., 1997) and their growing discrepancy is worrisome for future work. As a consequence of this divergence, the solar and geomagnetic precursors should be considered as separate categories.

An a priori estimate of the upcoming cycle that has a smaller uncertainty than the climatological average should be developed and provided to researchers interested in predicting solar activity. The rather large standard deviation in $R_{z \text {,ave }}\left(\sigma_{0}=40\right.$ or $\left.30 \%\right)$ means that only extremely large or small predictions would be considered highly statistically significant. Other techniques of ranking solar cycle forecasts, such as the skill scores described by Wilks (1995), could be used to more accurately assess the validity of the various methods. Weather forecasters had to develop similar metrics as numerical weather models became possible (Lynch, 2008).

Even when the level of solar activity can be forecasted with reasonable accuracy, the prediction of exceptional events will always provide new challenges. These include solar radio bursts that overwhelm GPS [such as on 6 December 2006 (NOAA, 2007)], solarenergetic-particle events that reach Earth without warning [often observed as ground level events or GLEs (Shea and Smart, 2000)], and the possibility of solar activity at a location on the disk is determined by conditions far from that location.

Given the wide range of the predictions for Solar Cycle 24, we look forward to this cycle answering important questions about how to predict solar activity.

Acknowledgements This work was done while the author was a member of the Solar Cycle 24 Prediction Panel, convened by NOAA's Space Weather Prediction Center and chaired by Douglas Biesecker. A summary of the panel's discussion, including an early version of Table 1, is available at http://www.swpc.noaa.gov/ SolarCycle/SC24/index.html.

Open Access This article is distributed under the terms of the Creative Commons Attribution Noncommercial License which permits any noncommercial use, distribution, and reproduction in any medium, provided the original author(s) and source are credited.

\section{References}

Badalyan, O.G., Obridko, V., Sykora, N.J.: 2001, Brightness of the coronal green line and prediction for activity cycles 23 and 24. Solar Phys. 199, $421-435$.

Baranovski, A.L.: 2006, Shape fitting modeling and nonlinear solar cycles forecasting, Prediction submitted 8 September 2006.

Biesecker, D.: 2007, The Solar Cycle 24 Prediction Panel, Consensus statement of the Solar Cycle 24 Prediction Panel, Released March 2007. http://www.swpc.noaa.gov/SolarCycle/SC24/.

Cameron, R., Schüssler, M.: 2007, Solar cycle prediction using precursors and flux transport models. Astrophys. J. 659, $801-811$. doi: $10.1086 / 512049$.

Chopra, P., Dabas, R.S.: 2006, Prediction of maximum amplitude of the next Solar Cycle 24 using modified precursor method. In: Proc. 36th COSPAR Scientific Assembly 36, 909.

Choudhuri, A.R., Chatterjee, P., Jiang, J.: 2007, Predicting Solar Cycle 24 with a solar dynamo model. Phys. Rev. Lett. 98, 131103. doi:10.1103/PhysRevLett.98.131103.

Clilverd, M.A., Clarke, E., Ulich, T., Rishbeth, H., Jarvis, M.J.: 2006, Predicting Solar Cycle 24 and beyond. Space Weather 4, S09005. doi:10.1029/2005SW000207.

Dabas, R.S., Sharma, K., Das, R.M., Pillai, K.G.M., Chopra, P., Sethi, N.K.: 2008, A prediction of Solar Cycle 24 using a modified precursor method. Solar Phys. doi:10.1007/s11207-008-9200-1. 
de Meyer, F.: 2003, A transfer function model for the sunspot cycle. Solar Phys. 217, 349-366.

Dikpati, M., de Toma, G., Gilman, P.A.: 2006, Predicting the strength of solar cycle 24 using a flux-transport dynamo-based tool. Geophys. Res. Lett. 33, L05102. doi:10.1029/2005GL025221.

Du, Z., Du, S.: 2006, The relationship between the amplitude and descending time of a solar activity cycle. Solar Phys. 238, $431-437$.

Duhau, S.: 2003, An early prediction of maximum sunspot number in Solar Cycle 24. Solar Phys. 213, 203 212.

Echer, E., Rigozo, N.R., Nordemann, D.J.R., Vieira, L.E.A.: 2004, Prediction of solar activity on the basis of spectral characteristics of sunspot number. Ann. Geophys. 22, 2239-2243. doi:1432-0576/ ag/2004-22-2239.

Euler, H.C. Jr., Smith, S.W.: 2006, Future solar activity estimates for use in prediction of space environmental effects on spacecraft orbital lifetime and performance. http://sail.msfc.nasa.gov/current_solar_report/ CurRpt.pdf. Results in table are from the September 2006 report.

Gholipour, A., Lucasa, C., Araabia, B.N., Shafiee, M.: 2005, Solar activity forecast: Spectral analysis and neurofuzzy prediction. J. Atmos. Solar-Terr. Phys. 67, 595-603.

Hamid, R.H., Galal, A.A.: 2006, Preliminary prediction of the strength of the 24th 11-year solar cycle. In: Bothmer, V., Hady, A.A. (eds.) Solar Activity and its Magnetic Origin, Proceedings of the 233rd Symposium of the IAU, Cambridge Univ. Press, Cambridge, 413-416.

Hathaway, D.H., Wilson, R.M.: 2004, What the sunspot record tells us about space climate. Solar Phys. 224, 5- 19 .

Hathaway, D.H., Wilson, R.M.: 2006, Geomagnetic activity indicates large amplitude for sunspot cycle 24. Geophys. Res. Lett. 33, L18101. doi:10.1029/2006GL027053.

Hiremath, K.M.: 2008, Prediction of solar cycle 24 and beyond. Astrophys. Space Sci. doi:10.1007/ s10509-007-9728-9.

Horstman, M.: 2005, Varying solar flux models and their effect on the future debris environment projection. Orbital Debris Q. News 9, 4-5.

Jain, R.: 2006, Prediction of the amplitude in sunspot cycle 24. 36th COSPAR 36, 642.

Janssens, J.: 2005, Solar Cycle 24: Overview of predictions on the start and amplitude of a new solar cycle. Accessed as http://members.chello.be/j.janssens/SC24pred.pdf.

Janssens, J.: 2006, Solar Cycle 24: Overview of predictions on the start and amplitude of a new solar cycle. Accessed as http://members.chello.be/j.janssens/SC24.html.

Javaraiah, J.: 2007, North-south asymmetry in solar activity: Predicting the amplitude of the next solar cycle. Mon. Not. Roy. Astron. Soc. Lett. 377, L34-L38. doi:10.1111/j.1745-3933.2007.00298.x.

Joselyn, J.A., Anderson, J.B., Coffey, H., Harvey, K., Hathaway, D., Heckman, G., Hildner, E., Mende, W., Schatten, K., Thompson, R., Thomson, A.W.P., White, O.R.: 1997, Panel achieves consensus prediction of Solar Cycle 23. EOS Trans. AGU 78, 205-212.

Kane, R.P.: 1999, Prediction of the sunspot maximum of solar cycle 23 by extrapolation of spectral components. Solar Phys. 189, 217 - 224.

Kane, R.P.: 2007, A preliminary estimate of the size of the coming solar cycle 24, based on Ohl's precursor method. Solar Phys. 243, 205 - 217.

Keeping, E.S.: 1962, Introduction to Statistical Inference, Van Nostrand, Princeton (Dover reprint published 1995).

Kennewell, J., Patterson, G.: 2006, Prediction submitted 11 September 2006.

Khramova, M.N., Krasotkin, S.A., Kononovich, E.V.: 2002, New aspects of solar activity forecast. In: Sawaya-Lacoste, H. (ed.) Solspa 2001, Proceedings of the Second Solar Cycle and Space Weather Euroconference SP-477, ESA, Noordwijk, 229-232.

Kim, M.-H.Y., Wilson, J.W., Cucinotta, F.A.: 2006, A solar cycle statistical model for the projection of space radiation environment. Adv. Space Res. 37, 1741 - 1748. doi:10.1016/j.asr.2004.11.036.

Kontor, N.N.: 2006, Statistics based regular extrapolation, Prediction submitted 28 August 2006.

Lantos, P.: 2006, The skewness of a solar cycle as a precursor of the amplitude of the next. Solar Phys. 229, 373 - 386. doi:10.1007/s11207-006-0128-z.

Li, K.-J., Gao, P.-X., Su, T.-W.: 2005, Estimating the size and timing of the maximum amplitude of Solar Cycle 24. Chin. J. Astron. Astrophys. 5, 539-545.

Lynch, P.: 2008, The ENIAC forecasts: A re-creation. Bull. Am. Meteorol. Soc. 89, 45-55.

Mandel, J.: 1964, The Statistical Analysis of Experimental Data, Wiley, New York (Dover reprint published 1984).

Maris, G., Oncica, A.: 2006, Solar Cycle 24 forecasts. Sun Geospace 1. http://www.stil.bas.bg/lHY/forms/ SUN_GEO200601.html.

Mariş, G., Popescu, M.D., Beşliu, D.: 2004, Solar Cycle 23 analysis. In: Stepanov, A.V., Benevolenskaya, E.E., Kosovichev, A.G. (eds.) Multi-Wavelength Investigations of Solar Activity, IAU Symposium 223, Cambridge Univ. Press, Cambridge, $127-128$. 
Nevanlinna, H.: 2007, Prediction submitted to panel.

NOAA: 2006, List of sunspot maximum and minimum 1610-present. Accessed as ftp://ftp.ngdc.noaa.gov/ STP/SOLAR_DATA/SUNSPOT_NUMBERS/maxmin.new.

NOAA: 2007, Press release accessed as http://www.noaanews.noaa.gov/stories2007/s2831.htm.

Podladchikova, T., Lefebvre, B., Van der Linden, R.: 2006, Peak sunspot number for Solar Cycle 24. Prediction submitted 12 September 2006.

Press, W.H., Flannery, B.P., Teukolsky, S.A., Vettering, W.T.: 1992, Numerical Recipes, 2nd edn. Cambridge Univ. Press, London, 610-612.

Prochasta, R.D.: 2006, Prediction submitted 12 September 2006.

Rabin, D.M.: 2007, Forecast of the amplitude of Solar Cycle 24 based on the disturbed days precursor. Bull. Am. Astron. Soc. 210, 92.05

Roth, M.: 2006, Prediction submitted 12 September 2006.

Schatten, K.: 2005, Fair space weather for solar cycle 24. Geophys. Res. Lett. 32, L21106. doi:10.1029/ $2005 G L 024363$.

Sello, S.: 2003, Solar cycle activity: A preliminary prediction for cycle \#24. Astron. Astrophys. 410, $691-$ 693. doi:10.1051/0004-6361:20031295.

Sello, S.: 2006, Update of prediction email dated 4 October 2006.

Shea, M.A., Smart, D.F.: 2000, Fifty years of cosmic radiation data. Space Sci. Rev. 93, 229-262.

Svalgaard, L., Cliver, E.W., Kamide, Y.: 2005, Cycle 24: The smallest sunspot cycle in 100 years?. Geophys. Res. Lett. 32, L01104. doi:10.1029/2004GL021664.

Thompson, R.J.: 1993, A technique for predicting the amplitude of the solar cycle. Solar Phys. 148, 383 389.

Thompson, R.J.: 2008, Prediction for Cycle 24 using minimum value of Ap (12-month average), Prediction submitted March 2008.

Tlatov, A.G.: 2006, Indices of solar activity minimum of sunspot cycles and prediction solar cycle 24, Prediction submitted 26 September 2006.

Tritakis, V., Mavromichalaki, H., Giouvanellis, G.: 2006, Prediction of basic elements of the forthcoming solar cycles 24 and 25 (years 2005-2027). In: Solomos, N. (ed.) Recent Advances in Astronomy and Astrophyiscs: 7th International Conference of the Hellenic Astronomical Society. AIP Conf. Proc. 848, 154-162. doi:10.1063/1.2347972.

Tsirulnik, L.B., Kuznetsova, T.V., Oraevsky, V.N.: 1997, Forecasting the 23rd and 24th solar cycles on the basis of MGM spectrum. Adv. Space Res. 20, 2369 - 2372. doi:10.1016/S0273-1177(97)00909-5.

Volobuev, D.M., Makarenko, N.G.: 2008, Forecast of the decadal average sunspot number. Solar Phys. 249, 121 - 133. doi:10.1007/s11207-008-9167-y.

Wang, J.-L., Gong, J.-C., Liu, S.-Q., Le, G.-M., Sun, J.-L.: 2002, The prediction of maximum amplitudes of solar cycles and the maximum amplitude of solar cycle 24. Chin. J. Astron. Astrophys. 2, 557-562.

Wilks, D.S.: 1995, Statistical Methods in the Atmospheric Sciences, Academic Press, San Diego.

Yule, G.U.: 1927, VII. On a method of investigating periodicities in disturbed series, with special reference to Wolfer's sunspot number. Phil. Trans. Roy. Soc. London A 226, 267 - 298.

$\mathrm{Xu}, \mathrm{T}$., Wu, J., Wu, Z.-S., Li, Q.: 2008, Long-term sunspot number prediction based on EMD analysis and AR model. Chin. J. Astron. Astrophys. 8, 337-342. 